\title{
RNA interference and viruses in mammalian cells
}

\author{
B Monsef
}

From 5th European Workshop on Immune-Mediated Inflammatory Diseases

Sitges-Barcelona, Spain. 1-3 December 2010

Abstract not submitted for publication

Published: 25 November 2010

doi:10.1186/1479-5876-8-S1-17

Cite this article as: Monsef: RNA interference and viruses in mammalian cells. Journal of Translational Medicine 2010 8(Suppl 1):17. 